\title{
Independência para o Incapacitado Físico Através da Reabilitação Vocacional (*)
}

\author{
Prof. Ladislau Pôrto e Dra. Sara Erlich
}

\begin{abstract}
A Revista do Serviço Público tem a honra de divulgar em suas páginas e trabalho elaborado pelo Prof. LadisLau Pôrto e pela Dra. Sara Erlich, da Universidade do Recife, mestres consagrados e cientistas autênticos, dos mais notáveis da América Latina, criadores dessa extraordinária Instituição que é o Centro de Recuperação Motora do Nordeste. Os autores dispensam qualquer apresentação, pois, seus trabalhos são amplamente conhecidos nos circulos universitários, técnicos e culturais do Pais. «Independência para o Incapacitado Fisico através da Reabilitação Vocacional» é uma contribuição da maior importância pelo seu conteúdo e suas nobres finalidades. Nenhum brasileito cônscio de suas responsabilidades poderia permanecer indiferente diante dos problemas versados pelo ensaio do Prof. Ladislau Pôrto e Dra. Sara ERlich: trata-se de um documento de profundo significado no campo médico-social e humano. Sua publicação pela Revista do Serviço Público prescinde de qualquer justificação adicional. A Redação resolveu acrescentar, em anexo, um documentário relativo ao Centro de Recuperação Motora do Nordeste a fim de proporcionar aos leitores um conhecimento objetivo acêrca da luta impressionante que os cientistas patricios vêm travando, no Nordeste, tendo em vista tesolver os dramáticos problemas vinculados aos incapacitados fisicos. Divulgando o presente trabalho, sente a Revista do Serviço Público que está cumprindo um dever de solidariedade humana e, ao mesmo tempo, prestando um grande serviço ao Pais. (Nota da Redação).
\end{abstract}

T ODo o nosso empenho de criar no Recife o primeiro Centro de Reabilitação para servir aos Estados do Norte e Nordeste do Brasil, carentes de qualquer assistência desta natureza, foi antes de tudo a vontade de servir a uma coletividade que ainda não despertou para êste transçendente problema humano e social.

(*) Jornal do Comércio, 17-10-58. 
Êste trabalho psicológico de influenciar coletividades indiferentes, talvez tenha sido e continua a ser o nosso mais ingente esfôrço e a nossa decidida obstinação. O nosso Estado ainda persiste ausente dos movimentos pioneiros. Advertimos que todo o êxito de nosso empreendimento está na dependência do interêsse coletivo, principalmente das classes mais favorecidas. Esta cômoda atitude de espectação destas mesmas classes, espectação que significa olhar o nosso movimento apenas aplaudindo sem ajudar, representa uma outra forma de indiferença inconstrutiva e talvez desumana.

O Centro de Reabilitação do Nordeste necessita desta ajuda e mais uma vez, parte de nós, êste apêlo, a fim de que todos os homens de boa vontade e de tôdas as classes sociais compreendam e sintam a necessidade de dar um pouco de sua colaboração concreta e humana.

Todos nós conhecemos pessoas vítimas de doença incapacitante. Muitas como que desaparecem de nossas vidas, passando a compor a população que povoa os mais diversos hospitais e instituições e sòmente os médicos, enfermeiras $e$ assistentes sociais tomam realmente conhecimento de suas existências. Através de um serviço de reabilitação apropriado, milhares dêles poderiam abandonar suas cadeiras de roda, seus leitos nos lares e nos hospitais e se tornar capazes de cuidar de si próprios, possuidos de um renovado interêsse pelo mundo em que vivem. Naturalmente que nem todos podem ser reabilitados, pois, algumas condições estão além do alcance da atual ciência médica, porém, grande parte pode ser recuperada e nós podemos e devemos trazê-los de volta à uma vida útil e digna.

A incapacidade física, atingindo súbitamente $o$ indivíduo, o obriga a se ajustar às limitações e adaptações impostas pela mesma, necessitando para isto modificar, de acôrdo com a natureza e extensão da incapacidade, a imagem de seu corpo, seu conceito de si próprio, suas relações com as demais pessoas e o seu trabalho. Êste ajustamento psicológico pode ter para o paciente implicações mais graves que a própria incapacidade em si. Devemos pensar em tudo isto e ajudá-lo a encontrar um novo rumo que sòmente poderá ser alcançado através da reabilitação vocacional.

A reabilitação vocacional é um serviço apoiado nos países mais adiantados por leis especiais e que se orienta no sentido de ajudar homens e mulheres fisicamente incapazes, a ganhar o seu próprio sustento e o de suas familias. Para isto, são submetidos a um programa completo de tratamento médico, orientação e treinamento de uma profissão de acôrdo com as suas possibilidades físicas e mentais e, em seguida, é cuidada a colocação em emprêgo adequa,do e ajustamento no mesmo. Tais serviços não representam uma caridade, mas, são planejados, como um direito legal para todos aquêles que os necessitam, possuindo a mesma categoria das escolas e hospitais públicos, proteção policial corporações contra o fogo etc.

Na América do Norte, cada Estado tem o seu serviço de reabilitação vocacional; funcionando em associação com o Govêrno. No fim de 1957. 990.000 homens e mulheres foram reabilitados e assim encaminhados para uma vida produtiva, através dos serviços de reabilitação vocacional. Desde $1943,780.000$ foram reabilitados. 
Aos serviços de reabilitação vocacional, recorrem os mais variados tipos de incapacitados com os mais diversos problemas físicos, emocionais e sociais: a) os que exerciam anteriormente um determinado tipo de profissão para o qual não são mais aptos depois da doença incapacitante; $b$ ) os que nunca trabalharam anteriormente; c) adolescentes que necessitam de uma orientação segura que lhes permita, de futuro, uma vida independente. Para a reabilitação vocacional, não se deverá levar em conta exclusivamente aquêles pacientes vítimas de acidente de trabalho e sim, qualquer caso de doença incapacitante, quer congênita, quer adquirida em acidente de trabalho ou por doença no decurso da vida.

Para que o indivíduo possa submeter-se a reabilitação vocacional, terá que preencher os seguintes requisitos:

1 - Ser possuidor de uma incapacidade que interfira substancialmente com a obtenção de um emprêgo remunerado.

2 - Possuir uma chance razoável de ser reabilitado, dentro de um período de tempo também razoável.

3 - Estar em idade (ou próxima) que lhe permita exercer uma profissão.

Constitui um grave êrro supor que os diversos serviços de reabilitação. possam ser unidos em «cúpula», pois, alẻm de ser uma orientação anticientífica, será criada pela imaturidade do problema entre nós, uma confusão e um desacêrto que sòmente servirá a certos burocratas impenitentes, que, sem o real alcance do problema, dão ao mesmo um critério de pura improvisação.

Para que a reabilitação seja realmente eficaz, os seus serviços se subdividem, nos diferentes campos, de acôrdo com a categoria de doentes que êles se destinam a reabilitar: cegos, surdos-mudos, tuberculosos, cardíacos, reumáticos, doentes egressos de clinicas psiquiátricas, etc. No Centro de Reabilitação do Nordeste, o setor destinado à orientação e reabilitação vocacional, se dedicará aos pacientes dotados de distúrbios neuromusculares, bem como, no setor destinado à educação de crianças surdo-mudas, não se fará pròpriamente a reabilitação vocacional e sim, se iniciará a orientação necessária, futuramente, a cada caso em particular.

E' necessário esclarecer que, sem o auxílio imediato do Govêrno e do povo em geral, o problema não terá solução: de que valerá tornar o incapacitado capaz de exercer uma profissão de acôrdo com as suas possibilidades se, após o seu adestramento, a própria sociedade se recusará a reconhecer as suas aptidões e a receber os seus serviços? Não devemos esquecer que êles têm igual direito que nós e, portanto, devem ter igual oportunidade, uma vez que são capazes de produzir, e o seu trabalho tem o mesmo valor daquele dos demais operários.

O ideal seria a formação de serviços especializados em reabilitação vocacional, contando com o apoió do Govêrno, comércio, indústria, escolas profissionais, hospitais, enfim, com a população de um modo geral. Naturalmente que êstes meios surgirão, à medida que aumentar entre nós ointerêsse pela reabilitação. 
No Centro de Reabilitação do Nordeste, os pacientes serão submetidos a um programa constando de:

1 - Diagnóstico médico para a avaliação da natureza e grau de incapacidade física e tratamento orientado no sentido de recuperar e desenvolver funções perdidas. Esta parte ficará a cargo do setor de medicina física e reabilitação.

2 - No setor psico-social, o psiquiatra fundamentará as suas instruções. nos achados psicológicos de uma ou mais entrevistas psiquiátricas com os paciente e os resultados que obtiver serão integrados com os do psicólogo e do assistente social, o que permitirá uma segura orientação e seleção de um trabalho adequado às possibilidades físicas e mentais de cada um.

O termo incapacitado fisico é relativo. Incapaz para que? Todos nós, somos, na realidade, incapazes para uma certa categoria de trabalho. Quantos de nós poderiam ser jogadores profissionais de futebol? Ou para-quedistas? As capacidades perdidas não devem ser levadas em consideração e sim as capacidades remanescentes que podem e devem ser canalizadas para um fim produtivo por meio da seleção adequada de um trabalho dentro das possibilidades de cada um. Ûm homem com uma só perna, terá naturalmente, limitada a sua capacidade de correr, levantar, carregar, porém, possui integras as suas habilidades manuais, seus sentidos, sua inteligência, não havendo lımitaçốes nos seus interêsses, aptidões, personalidade ou hábitos de trabalho.

$A_{5}$ estatisticas americanas mostram que os incapacitados físicos são capazes de uma produção não quase tão boa ou tão boa quanto a dos demais operários e sim, estudos neste campo confirmam que, desde que possuam a chance de trabalhar num emprêgo para o qual foram devidamente instruidos. alcançam cifras de trabalho melhores que as dos demais operátios. As estatisticas demonstram que êles se ajustam rápida e satisfatòriamente às: condições de trabalho; são produtivos, cuidadosos assíduos, dignos de confiança. Enfim, são capazes.

Na América do Norte, esta nova éra na história da reabilitação voca :ionaI foi iniciada em 3 de agôsto de 1954, quando o Presidente Eisenhower promulgou uma lei, concedendo aos fisicamente incapazes o direito de ocupar um cargo adequado às suas possibilidades. Isto asseguraria o seu próprio sustento e o de suas familias, diminuindo, consideràvelmente, os encargos: dos podêres públicos uma vez que não seriam mais obrigados a manter êstes cidàdão e suas famílias. $O$ interêsse e a fiscalização, neste sentido são tão intensos que há um dispositivo na lei de pagamento aos incapacitädos, estipulando a redução ou mesmo a suspensão dos benefícios por êles recebidos, desde que se recusem sem justificativa aplausivel, a aceitar os beneficios da reabilitação, quando tais serviços seriam eficazes no caso.

A economia da reabilitação conta, nos Estados Unidos, uma história impressionante. Durante 14 anos, nos quais, um programa Federal-Estadual forneceu a recuperação física ao lado de outros serviços aos incapacitados físicos, mais de 778.000 homens e mulheres foram reabilitados pelas agências de reabilitação vocacional. A maioria das 66.000 pessoas estabelecidas em trabalho produtivo em 1956, não tinham salário, pôsto que, nesta época, 
iniciaram a receber os serviços da reabilitação. Aquêles poucos que estavam recebendo salários, ganhavam juntos cêrca de $\$ 17,5$ milhões por ano: a maioria em emprêgo temporários, perigosos e pouco apropriados. Depois de sua reabilitação, colocados em emprèos adequados às suas possibilidades físicas e mentais, estas 66.000 pessoas estavam ganhando cêrca de $\$ 127,3$ milhões por ano. Dentro de 3 anos, os homens e mulheres reabilitados em 1956 devolverão ao Tesouro Federal mais do que os $\$ 30$ milhões gastos pelo Govêrno Federal durante os anos de apoio básico aos programas de reabilitação. Avalia-se que, durante tôda a vida de trabalho produtivo, pagarão, em impôsto de renda Federal, cêrca de $\$ 10$ por cada dólar Federal gasto nestes programas.

Entre nós, uma vez que não dispomos de serviços especializados, destinados, à reabilitação vocacional, a solução dêstes problemas será mais difícil e só será possível com a colaboração do Govêrno e a boa vontade do povo em geral.

Desde que, depois da seleção adequada, os pacientes puderam receber a instrução necessária ao exercício de sua nova profissão, no setor de terapêutica ocupacional do próprio Centro de Reabilitação do Nordeste, o problema será menor. A maior parte porém, necessitará de instrução relativa aós diferentes setores do comércio, indústrias, oficinas, escritórios, hospitais, escolas, edifícios públicos, etc., e para isto necessitamos esclarecer a opinião pública no sentido de apagar velhos e enganosos preconceitos relativos ao emprêgo de operários fisicamente incapazes.

Parao ataque e solução dêstes problemas, várias medidas deverão ser tomadas:

1 - Leis que concedam aos nossos incapacitados físicos o direito de exercer uma profissão desde que devidamente instruidos e aptos para a mesma. Estas leis deverão estender-se também aos demais Estados afim de que, reabilitados aqui, não possam deixar de exercer a profissão para a qual forem preparados, no seu lugar de origem. No Brasil, a ilustre deputado Fernando Ferrari apresentou recentemente um projeto de lei visando a proporcionar ao incapacitado o exercício de funções públicas ou outra qualquer atividade compatível com o seu desenvolvimento psicofísico.

2 - Campanha de esclarecimento ao povo, afim de fazê-lo compreender que, uma vez reabilitados, os incapacitados físicos não mais necessitam, nem solicitam consideração especial e sim, uma igualdade de oportunidade de lutar por uma vida útil e digna.

Capacidade - não incapacidade - é o que deveremos considerar.

3 - Acôrdo com os diferentes setores de comércio, indústria, escolas, hospitais, oficinas, edifícios públicos, etc., relativo ao emprêgo, nos seus serviços, de pessoas fisicamente incapazes, reabilitados, isto é, aptas a exercer uma profissão.

4 - Acôrdo com o Govêrno no sentido de fornecer verbas destinadas a:

a) Compra de material protético (membros artificiais, auxiliares auditivos, etc). 
b) Compra do instrumental de trabalho e fornecimento de pequeno capital, quando êstes forem necessários para conferir à reabilitação individual uma base estável.

c) Pagamento de instrutores mobilizados nos diferentes setores comerciais, industriais, escolares, hospitalares, etc., que se encarregarão de instruir 0 incapacitado físico.

5 - A instrução necessária a cada caso em particular. poderá ser efetuada no próprio futuro local de trabalho em horas preestabelecidas ou no próprio lar, quando possivel.

6 - As assistentes sociais do Centro de Reabilitação do Nordeste manterão o contacto entre o fisicamente incapaz e o Centro de Reabilitação, até que esteja devidamente colocado e adaptado ao emprêgo.

7 - Os próprios institutos de previdência social, através de seus órgãos competentes, poderiam criar uma legislação, especial, contendo os meios necessários de instrução e ajustamento profissional obrigando os diferentes setores da atividade humana à conservação de vagas para o aproveitamento do incapacitado físico.

Necessitamos compreender que a caridade não é a solução para o problema do fisicamente incapaz. O que êle merece é uma igual oportunidade de lutar pela sua própria subsistência. Elle não deve permanecer como um marginal e o único meio seguro de evitar isto e de lhe proporcionar a independência econômica, social e bem-estar espiritual, é através de um trabalho que o faça sentir-se útil a si, à sua familia e à sociedade. Além de constituir um ato de justiça de nossa parte, estas medidas pouparão, cada ano, uma importância considerável ao Govêrno.

Depois de tudo que foi exposto, não é mais preciso salientar o valor transcendente que os serviços de reabilitação vocacional poderão prestar às coletividade do Brasil. Se continuarmos a dar as costas para êste problema, mais cedo ou mais tarde os cofres dos institutos de previdência social do nosso país estarão vazios, em visła da soma considerável de inválidos que além de viverem das minguadas pensúes para o seu sustento e o de suas famílias, ficam condenados a um permanente relegamento no seio das coletividades. O seu ôtuus representa um desperdicio e suas vidas sofrem as mais dolorosas restrições.

A nossa tarefa, depois de inaugurado o Centro de Reabilitação do Nordeste, é incentivar tôdas as camadas sociais e os Governos das diversas regiões do Norte e Nordeste e, uma vez contando com o apoio do Govêrno e do povo em geral, iniciar a primeira tentativa de realizar a reabilitação vocacional entre nós, pois, só assim poderemos, a exemplo dos Estados Unidos, comprovar que o incapacitado físico é, muitas vêzes capaz de realizar o que muitos capazes não são.

Enfim, a solução para o problema do fisicamente incapaz é uma só reconstituir e promover aptidões que a doença fez crestar, dando ao mesmo tempo uma forma humana e produtiva à sua própria sobrevivência. 


\section{BIBLIOGRAFIA}

1 - Independence for the handicapped.

A review of progress in rehabilitation and employment of the handicapped Prepared by the Office of Vocatinal Rehabilitation.

U.S. Department of Health, Education and Welfare

2 - Doing something for the disabled

September 1957

Mary E. Switzer and Howard A. Rusk

$$
\text { June } 1953
$$

3 -- Help for the disabled through vocational rehabilitation U.S. Department of Health, Education and Welfare

4 - New Hope for the disabled

November 1957

U.S. Department of Health, Education and Welfare

5 - Office of Vocational Rehabilitation

$$
\text { July } 1957
$$

From the annual report of the U.S. Department of Health, Education and Welfare

\section{DOCUMENTÁRIO ANEXO}

Rio de Janeiro, Estado da Guanabara, 2 de maio de 1960

Do Conselheiro Araújo Cavalcanti (Território Federal do Rio Branco)

Ao Presidente da ABM, Conselheiro Lomanto Júnior (Prefeito de Jequié, Bahia).

Assunto: O Centro de Recuperação Motora do Nordeste. Colaboração Positiva da Associação Brasileira dos Municipios na Execução Magno Empreendimento. O trabalho excepcional do Prof. Ladislau Pôrto e da Dra. Sara Erlich. «Problemas psicológicos, vocacionais e sociais na reabilitação dos incapacitados físicos». Üma contribuição científica brasileira ao Congresso de San Diego (Califórnia, U.S.A.).

Senhor Presidente:

O Centro de Recuperação Motora do Nordeste é uma instituição pioneira que tem como finalidade primordial promover a reabilitação física, psicológica, vocacional e social do incapacitado. Destina-se, além disso, á investigação científica, ensino técnico, documentação especializada, intercâmbio e divulgação no tocante aos problemas situados no âmbito de suas atribuições específicas. No conjunto de suas múltiplas atividades, o Centro de Recuperação Motora do Nordeste avulta como um empreendimento de vastas proporções, profundamente humanitário pelos seus objetivos, planejado e realizado pelo Prof. Ladislau PôRto, com a assistência técnica permanente da Dr. Sara ERLICH - duas personalidades insignes no campo da Ciência e da Técnica.

2. Por ocasião do V Congresso Nacional dos Municipios Brasileiros, levado a efetito na cidade do Recife, de 1 a 8 de dezembro de 1959, - os 
prefeitos, vereadores, autoridades, técnicos e estudiosos que tiveram oportunidade de conhecer, de perto, a obra incomparável do Prof. LADisLAu PÔRTo e da Dra. SARA ERLich, aprovaram, por unanimidade, uma consagradora Indicação relativa ao Centro de Recuperação Motora do Nordeste, e além disso, durante a sessão magna presidida pelo Ministro da Saúde, Dr. Mario PinOtTI, prestaram, aos dois cientistas, uma homenagem comovedora que foi, talvês, o ponto mais alto do Congresso do Recife.

3. A Indicação aprovada pelo $\mathrm{V}$ Congresso Nacional dos Municípios resultou, por sua vez, da aprovação, também por unanimidade, nas Comissões Técnicas e no Plenário do mencionado Congresso, da Tese então apresentada pelo Centro de Recuperação Motora do Nordeste, intitulada "Problemas Psicológicos, vocacionais e Sociais na Reabilitação do Incapacitado Físico", de autoria do Prof. Ladislau Pôrto e Dra. Sara Erlich. Essa Tese, incontestàvelmente, é, sob muitos aspectos, um dos mais importantes trabalhos, de nivel universitário superior, já elaborados em nosso País. A Assessoria Técnica do Congresso do Recife, não sòmente manifestou integral apoio e irrestrita solidariedade as reivindicações do Centro de Recuperação Motora do Nordeste, como fez questão de aplaudir a iniciativa dos eminentes Autores, e propõe:

a) aprovação imediata da Tese do prof. Ladislau Pôrto e Dra. Sara ERLICH, bem como da Indicação dela decorrente;

b) encaminhamento do trabalho do Centro de Recuperação Motora do Nordeste ao Senhor Presidente da República e ao Ministério da Saúde;

c) remessa, também urgente, da Indicação e da Tese, em aprêço, ao Govêrno do Estado de Pernambuco;

d) transcrição dos aludidos trabalhos nos Anais do V Congresso dos Municipios;

e) finalmente, que os prefeitos, vereadores e municipalistas de todo o Brasil se pronunciassem sôbre a matéria, prestigiando o Centro de Recuperação Motora do Nordeste, e destarte, colaborando com as figuras exponenciais do Prof. Ladislau Pôrtb e da Dra. Sara Erlich, no sentido de consolidar e fortalecer um empreendimento que, efetivamente, merece os aplausos do Povo Brasileiro».

4. Seria impossivel relatar a amplitude e intensidade dos sacrifícios de tôda a ordem dos beneméritos realizadores do Centro de Recuperação Motora do Nordeste - uma luta tenaz, sem tréguas, contra fatôres adversos consubstanciados na falta de recursos financeiros e na inflexibilidade de uma burocracia insensivel, paralisante, retardatária. Todavia, com aquela admirável tenacidade caracteristica dos idealistas obstinados, o Prof. Ladislau PôrTo conseguiu obter uma doação do Presidente JusCelino KuBITSCHECK no valor de US\$ 23 mil dólares (US\$ 23,000,00) para aquisição dos equipamento básicos de reabilitação, de procedência norte-americana - já adquiridos na Preston Corporation de Nova York, equipamentos êsses embarcados e depositados na sede do DNOCS.

O prédio destinado à localização do Centro de Recuperação Motora do Nordeste foi desapropriado por Lei da Assembléia Legislativa do Estado de 
Pernambuco, convindo, todavia, acentuar que o edifício da rua Fernandes Vieira, 600, na cidade do Recife, continuará a pertencer ao Estado, servindo, apenas, para o funcionamento da Instituição que dará assistência gratuita aos doentes indigentes, esperando-se, para dentro de cinco meses a sua inauguração. O problema máximo, no entanto, - a utilização e emprêgo de pessoal especializado nos diversos dominios da reabilitação - embora equacionado, aguarda uma solução adequada. Neste sentido, através do D.A.S.P., estão sendo ultimados os contratos de especialistas europeus e norte-americanos, os quais, além de trabalhar no Centro, terão, também, a incumbência de manter cursos para formação da primeira Equipe de técnicos em reabilitação do Norte e do Nordeste do Brasil. A orientação científica deverá obedecer ao Prof. Howarn Rusk, pai da reabilitação mundial, Diretor do Instituto de Medicina Física e Reabilitação do Centro Médico de Bellevue, da Universidade de Nova York. O Prof. LAdislau PôRTo vem mantendo permanentes entendimentos, desde longa data, com os mais renomados especialistas, como, por exemplo, o Prof. JeAn Dayez, Catedrático de Fisioterapia e Reabilitação da Faculdade de Medicina de Madrid; a Diretora da American Occupational Therapy Association, Miss Helen C. Mathias, de Nova York; os Técnicos de The Institute of British Surgical Technicians, de Londres; afora eminentes especialistas suecos e alemães em assuntos de eletroencefalografia, eletromiografia, próteses e aparelhos ortopédicos, fisioterapia, etc. Encontra-se, ainda, o Prof. LAdislau PôRTo articulado com a Organização Muncial de Saúde (Escritório Regional de Copenhague) lutando para conseguir dessa Entidade facilitar o contrato dos técnicos em reabilitação tão necessários, em nosso País, principalmente em face da incidência da poliomielite, cada vez mais grave nas regiões subdesenvolvidas do Norte e do Nordeste. Infelizmente, como é do conhecimento dos Senhores Conselheiros da A.B.M. o contrato de especialistas se apresenta ainda mais dispendioso e dificil do que a obtenção do equipamento especializado. Por êste motivo apelou o Centro de Recuperação Motora do Nordeste para o Govêrno Federal havendo o D.A.S.P. incluído dotações no Orçamento Geral da União as quais, todavia jamais se materializaram, incluidas que foram nos chamados "Planos de Economia" e sacrificadas em nome de uma mal compreendida e inepta "contenção das despesas públicas" ... No âmbito do Poder Legislativo, o insigne Deputado Nilo Coelho apresentou o Projeto de Lei $n^{\circ}$ 2.996/57 (Autoriza o Poder Executivo a abrir, pelo Ministério da Saúde, o crédito especial de Cr\$10 milhões (dez milhões de cruzeiros) destinados às despesas do Centro. Mas, a tramitação dos Projetos de Lei dessa natureza, nas duas Casas do Congresso Nacional, é sumamente morosa e a magnânima tentativa do parlamentar pernambucano ainda não logrou os resultados colimados. De vez em quando, levantam-se, no Parlamento, críticas veementes contra a morosidade típica da elaboração legislativa. Assim, Projetos como o 2.996 /57 permanecem estagnados, apesar da boa vontade e do esforç̧o de alguns parlamentares mais sensiveis aos problemas da reabilitação. Ainda recentemente, o Deputado Andrade Lima Filho, por duas vêzes, da tribuna da Câmara, reclamou providências e formulou dramáticos apelos ao Ministro MáRIO PINOTTI solicitando a intervenção direta do Ministério da Saúde para uma solução definitiva dos problemas do Centro 
de Recuperação Motora do Nordeste. Enquanto prossegue, na Câmara dos Deputados o andamento daquela e de outras proposições semelhantes, deliberou o incansável Prof. LADIsLAu PôRTo dirigir-se, novamente, ao Poder Executivo. Neste sentido encaminhou, a $1^{\circ}$ de dezembro de 1959 , ao ilustre Diretor Geral do D.A.S.P. Prof. JoÃo GuIllerme DE ArAgão, uma Exposição de Motivos relativa ao Centro de Recuperação Motora do Nordeste, solicitando, mais uma vez, a prestigiosa colaboração do D.A.S.P. no tocante à solução dos problemas consubstanciados no binômio aparelhagem técnica - contrato de especialistas. Coube-me a honra de, pessoalmente, entender-me com o Diretor-Geral do D.A.S.P., a quem fiz entrega da Exposição do Centro de Recuperação Motora do Nordeste. O Prof. JoÃo Guilherme de ArAgão determinou, de imediato, a Divisão de Orçamento e Organização do D.A.S.P., o estudo dos aludidos problemas tendo em vista encontrar uma solução para os mesmos. Em virtude do interêsse pessoal e do empenho todo especial do Prof. João GuIlherme de ArAgÃo, a Divisão de Orçamento deu prioridade à referida Exposição (Processo n.: $26.647 / 59$, do D.A.S.P.) encontrando-se, no momento, o Prof. Ladislau Pôrto na expectativa de providências concretas do Govêrno Federal - quer diretamente, quer através de auxílios do Ponto IV, ou por intermédio da fórmula que o D.A.S.P. julgar mais convenjente a uma pronta solução do problema. Nos têrmos da Exposição do Professor LAdislau PôRTo, os especialistas a serem contratados seguirão um rigoroso programa de trabalho, durante os prazos estipulados nos respectivos contratos. O Centro de Recuperação Motora do Nordeste, visando o reajustamento psicofísico do inválido, concentrará seus esforços e atividades, de início, em três Setores prioritários:

1) Medicina Fisica e Reaibiitação, compreendendo seções de exames, exercícios, eletroterapia, hidroterapia, terapêutica ocupacional e recreação terapêutica;

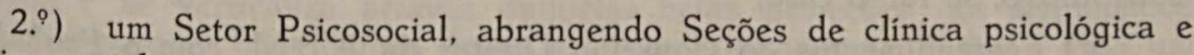
serviço social;

3) um Setor dedicado á educação da palavra e da linguagem. A cada Setor corresponderá, simultâneamente, um programa correlato de pesquisas e cursos, abrangendo, no conjunto: paralisia infantil e tôdas as suas seqüelas; seqüelas de mielites agudas; hemiplegias conseqüentes às mais variadas etiologias; tumores e acidentes vasculares do encéfalo; traumas cranianos com contusão e lesões cerebrais; lesões dos plexos e dos nervos periféricos; paraplegias das mais variadas ordens; seqüelas de traumatismos e compressões raquimedulares; desvios da coluna; reeducação de certas doenças familiares do sistema nervoso: Friedreich e Little; paralisia cerebral; osteoartrite; artrite reumatóide, etc.; reeducação da voz e da palavra; deficits intelectuais (oligofrenias).

5. Levando em consideração as minhas responsabilidades como Chefe da Assessoria Técnica do Congresso do Recife e, notadamente, as imperativas recomendações do V Congresso Nacional dos Municipios Brasileiros decorrentes da aprovação, por unanimidade, da Tese e da Indicação relativas ao Centro de Recuperação Motora do Nordeste; considerando, ainda, a 
participação brilhante do Prof. Ladislau Pôrto e da Dra. SARA ErLich nas Comissões Técnicas do referido Congresso; tendo em vista que o Centro de Recuperação Motora do Nordeste deverá atender as necessidades de 11 (onze) Estados da Federação Brasileira, do Amazonas a Bahia; considerando, finalmente, que nessa vasta área do nosso País não existe nenhuma Instituição capaz de lutar contra a grave problemática do fisicamente incapaz - principalmente o imenso número de crianças atacadas de poliomielite que, sem o concurso e a permanente assistência de uma Entidade especializada, ficarão condenadas a uma desoladora e injusta invalidez - cumpre-me requerer ao egrégio Conselho Diretor da A.B.M., por intermédio de seu Presidente, Prefeito LOMANTO JúnIoR, providências concretas e urgentes de irrestrito apoio às reivindicações do Centro de Recuperação Motora do Nordeste. Neste sentido, destaco, desde já, as seguintes providências que tenho a honra de sugerir aos Senhores Conselheiros da A.B.M.:

1\%) Audiência do Conselho Diretor da A.B.M. com os Senhores Presidente Juscelino Kubitscheck e o Ministro da Saúde, Dr. Mário Pinotti - presentes o Prof. Ladislau Pôrto e Dra. Sara Erlich - para um exame conjunto dos problemas da reabilitação dos incapacitados físicos do Norte e Nordeste do País e, especificamente, a consolidação definitiva do Centro de Recuperação Motora;

$2^{\circ}$ ) a mobilização do Grupo Parlamentar Municipalista, em reunião conjunta dos Deputados e Senadores que o integram com o Conselho Diretor da A.B.M. afim de ser encontrada uma fórmula que permite acelerar a votação do Projeto de Lei do Deputado Nilo Coelho, relativo ao Centro de Recuperação Motora do Nordeste (Projeto n 2.296-A, de 1957, já com pareceres favoráveis das Comissões. Publicado no Diário do Congresso Nacional, Seção I, sábado, 22 de novembro de 1958); elaboração de um substitutivo, se fôr o caso;

3\%) entendimentos do Conselho Diretor da A.B.M. com o Prof. Jox̃o Guil.herme de Aragão, Diretor-Geral do D.A.S.P., com vistas ao problema de contrato de especialistas alienígenas, objeto do Processo n. $.^{\circ} 26.647 / 59$ em andamento na Divisão de Orçamento do D.A.S.P., ou, nesta data, possìvelmente já na dependência de medidas da alçada do Ministério da Saúde.

$\left.4^{\circ}\right)$ audiência especial do Conselho Diretor da A.B.M. com o Ministro Conselheiro Howard R. CotTAM, Diretor da Missão Americana de Cooperação Técnica no Brasil, para exame das possibilidades de enquadramento do Centro de Recuperação Motora do Nordeste nos programas bilaterais de assistência financeira e técnica do Ponto IV. Aproveitar a oportunidade dêsse encontro para obtenção de 4 ou 5 Bôlsas de Estudo para a A.B.M.;

$\left.5^{\circ}\right)$ entendimentos do Conselho Diretor da A.B.M. com o Governador Cid Sampaio e com o Reitor Magnifico da Universidade do Recife para as medidas que se fizerem necessárias, no âmbito estadual, destinadas a facilitarem a plena execução das obras e serviços do Centro de Recuperação do Nordeste. Entendimentos visando idênticos objetivos, com o Prefeito do Recife, Dr. Miguel Arrais; 
69) requerimento, do Conselho Diretor da A.B.M. ao Dr. AlbErto SÁ Souza de Brito Pereira, Diretor do Departamento de Imprensa Nacional, solicitando urgência para publicação do trabalho intitulado «Problemas Psicológicos, Vocacionais e Sociais na Reabilitação dos Incapacitados Fisicos» (Tese de autoria do Prof. Ladislau Pôrto e Dra. SARa Erlich, aprovada pelo V Congresso dos Municipios, no Recife, em dezembro de 1959. Esta publicação que honra a cultura brasileira já se encontra na Imprensa Nacional desde fevereiro do corrente, sob o número de ordem de «Orçamento 257.346» - código da Imprensa Nacional, para fins de identificação. A Tese em aprêço foi encaminhada à Imprensa Nacional pelo Secretário-Geral do Instituto Brasileiro de Ciências Administrativas para publicação na Série D.A.S.P. - IBCA, e deverá ser apresentada ao Congresso de San Diego, em outubro vindouro, na Califórnia, U.S.A., como uma contribuição brasileira, por intermédio do Mayor Charles Dail.);

$\left.7^{9}\right)$ finalmente, planejamento e execução de uma Campanha Financeira, através do Setor competente da A.B.M., destinada a angariar fundos para o reajustamento psicofísico das crianças inválidas, sob a orientação técnica do Centro de Recuperação Motora do Nordeste.

6. Na certeza antecipada de que o Conselho Diretor da A.B.M. consciente das altas finalidades médicas, humanas e sociais características do Centro de Recuperação Motora do Nordeste - envidará todos os esforços para uma colaboração positiva na execução de seu magno Empreendimento, subscrevo-me, cordialmente. - Araújo Cavalcanti, (Representante do Território do Rio Branco no Conselho Deliberativo da A.B.M.)

Exmo. Sr. Presidente Juscelino Kubitscheck

Meu caro Presidente:

A linguagem que falo nesta hora transcende aquêles tristes horizontes formais e se verticaliza através daquelas belas projeções dos sentimentos humanos porque, falar dentro destas estruturas autônomas, é dar à vida um novo rumo, um outro curso e, ainda mais, abrir perspectivas amplas para outros destinos. E' que a fonte dêstes alcances subjetivos, o homem só consegue penetrar estendendo as mãos e erguendo os braços para colher aquêles dôces frutos que se fecundam pela fôrça das solidariedades efetivas.

Servir é o mais puro autêntico da vida. Porque, tôda a mobilização dêste sentimento se eterniza no infinito do tempo.

E aqui, conto a história de uma luta irrompida pela dor de conflitos afetivos e guardo em mim, numa vivência eterna, aquêle contacto de há quase 3 anos quando, estive em sua presença e senti o sensivel do seu acolhimento e compacto de sua solidariedade. Naquela hora de angústia, o desespero inquietava as minhas entranhas feridas.

Teria que escolher entre o estático de uma dor sem esperanças e o dinâmico de uma mágoa construtiva e criadora. Preferi o segundo plano dentro dêstes aturdimentos afetivos. Criei o Centro de Recuperação Motora do Nordeste, instituição pioneira em onze Estados do Norte e Nordeste do Brasil, na luta pelo reingresso de muitas vidas postas à margem por um infortúnio. Dei ao meu filho o que êle poderá dar a todos porque uma 
construção de sentimentos deve ser modelada pelo impessoal do bem comum. Reparti com êle o mesmo quinhão que darei aos que, como êle, necessitam de braços estendidos e de ternuras humanas. Dividi-me para alcançar o todo.

E agora e por fim, meu caro Presidente, deixo em suas mãos sensiveis um novo apêlo que, certamente, irá encontrar, no intimo do seu coração, aquela ressonância que é o mais puro autêntico de sua vida.

Recife, 6 de dezembro de 1959.

LADISLAu PÔRTO

$\mathrm{X} \quad \mathrm{x} \quad \mathrm{X}$

\section{RECUPERAÇÃO MOTORA}

8. O professor Ladislau Pôrto enviou a seguinte carta ao deputado Almany Sampaio:

«Recife, 21 de junho de 1960.

Ilustre Deputado Almany Sampaio:

O gesto de V. Excia., requerendo à Mesa, da Assembléia, um voto de gratidão do povo pernambucano ao Exmo. Sr. Presidente da República, por ter o mesmo liberado uma verba para a aquisição de um prédio onde vai ser sediado o Centro de Recuperação Motora do Nordeste, tem uma alta significação histórica e humana, porque com êste novo auxílio do eminente brasileiro Presidente Juscelino Kubitscheck, será iniciada uma nova era na. luta pela reabilitação dos incapacitados físicos de tôda área nordestina.

O sentido humano e social desta doação, Sr. Deputado, se distancia daqueles tristes imediatismos e marca, na sua universalidade a ajuda construtiva e fecunda que o tempo nunca poderá destruir. Porque um govêrno. Si. Deputado, representa apenas a interinidade de um poder, e a ação humana estratifica o eterno de sua permanência. Fácil é situar-se entre as fatuidades humanas, misturando-se naquelas tristes vaidades efêmeras; 0 difícil é criar o compacto de uma autenticidade que desafia a nomenclatura do tempo. O homem só se afirma por esta permanente autenticidade e por mais que os empréstimos das vaidades mediocres tentam colorir êste teor específico, o que subsiste dêste choque grotesco e triste é tão sòmente o inevitável desumano de certas esterilidades insensiveis. Por que Sr. Deputado, o que poderia fazer a criança estendida ao leito, num apêlo de braços e de coração, se a presença da solidariedade humana não lhe fizesse consolar o seu gemido de dor? E, mais ainda, Sr. Deputado, o que restaria de nós, se dentro de nossos olhos a ternura humana não fecundasse o melhor dos mundos? Por que virar as costas para aquêles anjos solitários de muletas, estendendo as mãos, solicitando ternura, possuídos da permanente aflição, reclusos que são do mundo em que vivem? Por que aumentar-se de tão

( ${ }^{\star}$ Carta do Prof. Ladislau Pôrto ao Presidente Juscelino Kubitscheck emcaminhando exposição relativo ao Centro de Recuperação Motora do Nordeste. 
graves problemas humanos e sociais, se um govêrno, é, antes de tudo, um depósito do bem comum? Não ajudar significa a triste exceção dêstes eternos critérios que devem existir em tôdas as geografias humanas. Situar-se dentro de isolacionismos inconstrutivos, em detrimento de coletividades sofredoras, significa, antes de tudo, possuir-se de uma algidez sem limites, frente àqueles belos acometimentos afetivos.

Por fim, Sr. Deputado, deixo em vossas mãos a mensagem de esperança que foi erguida pelo Presidente Juscelino Kubitscheck e por V. Excia. acolhida e divulgada para servir a todos aquêles que necessitam de braços estendidos e de ternuras humanas.

a) Ladislau Pôrto».

(*) Quarta-feira ,22 de junho de 1960. - Jornal do Comércio.

$* \quad \% \quad 3$

Para que o Centro de Recuperação Motora do Nordeste entre a funcionar quase que falta apenas uma coisa; que lhe permitam instalar-se num prédio. Ora, a desapropriação dêsse prédio já foi decretada, e falta apenas um ato do govêrno abrindo o crédito para fazê-la efetiva. É muito pouco portanto, o que falta, e nada justifica, nesta altura, que se retarde mais o almejado desfêcho.

Desfêcho duma longa e infatigável luta que um grupo de especialistas, à frente dos quais o Dr. Ladislau Pôrto, vem conduzindo desde muito tempo. E possivel que a muitos tenha passado desapercebido até agora o alto interêsse de que se reveste êsse propósito. Talvez haja mesmo os que admitam como tolerável o retardamento sofrido até agora, seja porque a necessidade é geral de nosocômios para uma população cujas taxas de sanidade são bem baixas, seja porque outros socorros haja, mais urgentes e prontos, que se devessem desenvolver de preferência. $\mathrm{Na}$ verdade, seria isso argumentar com a complexidade do quadro para subestimá-la. O campo a que a chamada Medicina Física e Reabilitação se aplica é realmente enorme. Tão grande quanto é grande a variedade de efeitos de incapacidade física decorrentes de um sem número de causas mórbidas da mais diversa espécie.

De sorte que sòmente num país em que a vida humana nada valha é que os esforços de recuperação motora poderiam ser tidos como dispensáveis. Aqui, se temos pelo menos, a justa vaidade de nos crermos como parte duma comunidade esclarecida, cumpre considerarmos como tarefa indispensável a reabilitação física de nossos semelhantes; para que não continuem a ser um pêso morto na sociedade de que participam e para que seja menor o número daqueles que a contragôsto deixam de concorrer para efeitos de convivência útil.

E de esperar, dessarte, que o govêrno, em cujas mãos está o desempenho do último ato dessa tenaz preparação dum serviço de tamanha importância, não o retarda mais. 